\title{
Examining health literacy disparities in the United States: a third look at the National Assessment of Adult Literacy (NAAL)
}

\author{
R. V. Rikard ${ }^{1 *}$ D, Maxine S. Thompson², Julie McKinney ${ }^{3}$ and Alison Beauchamp ${ }^{4}$
}

\begin{abstract}
Background: In the United States, disparities in health literacy parallel disparities in health outcomes. Our research contributes to how diverse indicators of social inequalities (i.e., objective social class, relational social class, and social resources) contribute to understanding disparities in health literacy.

Methods: We analyze data on respondents 18 years of age and older $(N=14,592)$ from the 2003 National Assessment of Adult Literacy (NAAL) restricted access data set. A series of weighted Ordinary Least Squares (OLS) regression models estimate the association between respondent's demographic characteristics, socioeconomic status (SES), relational social class, social resources and an Item Response Theory (IRT) based health literacy measure.

Results: Our findings are consistent with previous research on the social and SES determinants of health literacy. However, our findings reveal the importance of relational social status for understanding health literacy disparities in the United States. Objective indicators of social status are persistent and robust indicators of health literacy. Measures of relational social status such as civic engagement (i.e., voting, volunteering, and library use) are associated with higher health literacy levels net of objective resources. Social resources including speaking English and marital status are associated with higher health literacy levels.

Conclusions: Relational indicators of social class are related to health literacy independent of objective social class indicators. Civic literacy (e.g., voting and volunteering) are predictors of health literacy and offer opportunities for health intervention. Our findings support the notion that health literacy is a social construct and suggest the need to develop a theoretically driven conceptual definition of health literacy that includes a civic literacy component.
\end{abstract}

\section{Background}

Health literacy is an important determinant of health inequities across groups. The definition of health literacy is evolving from a focus on clinical risk to a focus on health literacy as an asset [1]. The clinical risk definition is prominent in the National Academy of Medicine's (formerly the Institute of Medicine) description of health literacy as an individual's capacity to obtain, process and understand basic health information and services needed to make appropriate health decisions [2]. The asset definition draws from public health and health promotion and directs attention to empowerment or "social and environmental factors that enable individuals to have

\footnotetext{
* Correspondence: rvrikard@msu.edu

${ }^{1}$ Department of Media \& Information, Michigan State University, 409 Comm

Arts, 404 Wilson Road, East Lansing, Ml 48824, USA

Full list of author information is available at the end of the article
}

greater control over health" [1]. More importantly, the clinical or risk approach reifies health literacy as an individual deficit instead of focusing on how social and economic factors work in tandem to impact population level health. Identifying health literacy as an asset, we explore determinants of health literacy using a relational social class model in conjunction with objective measures of social class. Objective indicators of social class signal differential access to resources but may not capture the mechanisms that link social inequalities to health literacy. In contrast, a relational view of social class asserts that connections to others through work, civic engagement, and social networks promote norms, values and benefits that facilitate obtaining and using health related information [3-5]. Relational social class represents social connections that are dynamic, fluid, and negotiable and thus are amenable to health promotion interventions. Our research 
contributes to knowledge of how diverse indicators of social inequalities contribute to an understanding of disparities in health literacy in the United States $[6,7]$. Moreover, our research objective is consistent with an emerging body of international health literacy research examining the social gradient in health literacy $[8,9]$.

Research studies observe an array of sociodemographic differences in the risk of low health literacy in the United States. Low health literacy is more prevalent among the elderly, men, racial/ethnic minorities, and low socioeconomic status (SES) groups [10-13]. The overall decline in physical and mental ability associated with aging may account for lower levels of health literacy among the elderly [13-15]. However, some challenges contribute to disparities in health literacy because they are more likely among low-income elderly. These include limited activities in daily living and more rapid cognitive decline [16-18]. Some research indicates that men have lower levels of health literacy compared to women [10, 13]; however, other research suggests the opposite [19, 20]. Similarly, the connection between race/ethnicity and health outcomes consistently indicates that compared to whites, racial/ethnic minorities have higher rates of morbidity and mortality [21] and lower levels of health literacy $[11,19]$.

Previous research using structural or objective indicators of social class (e.g., income, education attainment, and occupational status) consistently reveals socioeconomic disparities in health literacy [10, 13, 16, 22-27]. Studies find a positive relationship between individual level of income and health literacy. For example, an increase of approximately $\$ 5000$ in personal income is associated with a significant increase in health literacy levels $[11,13,28]$. Educational attainment shapes individuals' social status by influencing accumulated knowledge, skills, resources, habits, and, in turn, health [29]. Higher levels of educational attainment translate into better overall health outcomes and higher levels of health literacy [10, 12, 20, 30, 31]. Likewise, high occupational attainment as measured by higher prestige, power or influence is associated with higher health literacy levels [32].

There are limitations to the use of income, educational attainment, and occupational status as determinants of health literacy. The rationale for using income follows that increased income provides additional access to health resources [33]. However, the relationship between income and health is confounded by reverse causality [34]; not only are poverty and low income a significant risk for poor health outcomes, but the experience of a severe chronic illness or disability may also reduce overall earning potential [17]. The connection between educational attainment and health is linear and positive. Yet, education does not completely capture access to resources, and is only significant to the extent that the associated skills and knowledge are socially valuable $[4,34]$. Occupational prestige is the mutual assessment of the status associated with the title of an employment position. Occupational status, however, is only applicable for working-age adults in the labor force [3,34] and occupational status may not capture all the social connections related to health literacy such as social empowerment. Moreover, income, educational attainment, and occupational status are of limited utility in terms of offering insight into the effect of SES position on health literacy as previous research indicates health literacy independently predicts health outcomes when controlling for structural indicators of socioeconomic position $[8,15]$.

Relational social class highlights the mechanisms that might reveal how individuals come to accumulate health literacy. Relational social class is the emergence of social groups as a result of interdependent economic relationships [3, 35]. Indicators of relational social class assess the relative degree of connection between individuals and larger social institutions. Class-based social relationships account for how and why members of a social class advance their economic and social well-being as well as access socially valued resources to the detriment of others $[3,36]$. These indicators may include economic inclusion, political participation, and civic engagement [37, 38]. Employment status is the degree of economic inclusion that either grants or denies individuals access to needed resources. Specifically, full-time employment compared to part-time employment, unemployment, and retirement, protects and fosters perceived health and overall physical health $[39,40]$. Moreover, full-time employment in the United States may include employer provided health insurance, which connects people to the system of health care. Voting is a form of political participation directly tied to the development and implementation of large scale public policy [41]. Voting may also grant people a critical sense of belonging to a community and having rights within that community [42]. Thus, voting connects people across vertical power gradients and creates ties to formal institutions [43]. Previous research reveals that individuals living in regions with high voting rates are significantly less likely to report poor self-rated health than individuals living in areas with low voter turnout [44, 45]. Civic engagement activities, such as volunteering and library use, are essential to build informal ties that may improve mental and physical health as well as access to health information [46-48]. Differential availability of and access to social resources are equally important to understand disparities in health literacy.

Social resources are normative social means that provide economic protection and benefits. Measures of social resources may include language spoken, marital status, and methods of seeking out health information 
$[37,38]$. Speaking the primary or dominant language is an essential component to integrate and navigate within a given social context $[49,50]$. In the United States, previous research reveals that Hispanics who only speak Spanish, compared to Hispanics who speak English and Spanish, experience greater disparities in use of healthcare services and health outcomes [50,51]. Marriage or living as a married couple confers increased economic stability, lower levels of depression, and higher levels of life satisfaction compared to people who never marry $[52,53]$. Access to multiple sources of health information provides the benefit of informed health decision making [10] and is associated with less ambiguous knowledge of health conditions [54].

Relational social class and social resources are examined in this study to provide greater insight into social inequality in health literacy. In general, we expect relational and social resource measures will have additional value in understanding the disparities in health literacy. Thus, we hypothesize that relational social class measures (i.e., full-time employment, voting, and volunteering) are significant positive predictors of higher health literacy levels, net of the demographic and objective SES (i.e., income, educational attainment, and occupational prestige) resources measures. We also hypothesize that access to social resources (i.e., native English speaker, marriage, and the number of health information sources) is significantly associated with higher levels of health literacy, net of the demographic and objective SES resources measures.

\section{Method}

\section{Data source}

Data come from the 2003 National Assessment of Adult Literacy (NAAL). The NAAL is a unique nationally representative data set that includes an Item Response Theory (IRT) based measure of health literacy as well as measures of relational social class, social resources, and objective social resources. The written informed consent for participation in the NAAL, sampling design, and complete sample size are described elsewhere [55]. The complete NAAL household sample of more than 18,000 respondents was limited to adults (i.e., 18 years of age and older) for an analytical sample of 14,592 respondents. The analyses were performed with approval from the Institutional Review Board at North Carolina State University.

\section{Measures}

\section{Dependent variable}

The health literacy measure is based on Item Response Theory which models the level of difficulty for a given item and an individual's performance (i.e., answering the question correctly) on the item [56]. Baldi \& colleagues [57] developed 28 of the 152 items to measure health literacy in the NAAL. Responses to 23 of the 28 items were originally scored correct, incorrect, omitted, or not reached (i.e., $1=$ correct, $0=$ incorrect, $8=$ omitted, and $9=$ not reached) and responses to 5 items were scored correct, partially correct, incorrect, omitted, or not reached (i.e., $1=$ correct, $2=$ partially correct, $0=$ incorrect, $8=$ omitted, and $9=$ not reached). We recoded omitted and not reached responses as incorrect and employed the more general Graded Response Model (GRM) [58] IRT model to estimate health literacy scores [59]. The IRT parameters and recoded item responses were entered into VisualDF $[60]^{1}$ to compute the health literacy values.

\section{Independent variables \\ Demographic}

Respondents' age was measured in years and was computed from information on the respondent's date of birth and the date of the NAAL assessment. Respondent's sex was coded as a dummy variable (i.e., $0=$ Male, $1=$ Female) with males as the excluded category. Responses to three questions determine respondents' race/ ethnicity. The first question asks: "Are you Hispanic or Latino?" The second question asks respondents their country of birth. Hispanic/Latino respondents born in the United States are coded as native born while respondents' born outside the United States are foreign born. If the respondent indicated that they were not Hispanic/Latino, then the third question asked respondents' to indicate their racial/ethnic group [61]. Each race/ethnic group category was coded as a separate dummy variable and white respondents were the excluded category in the analyses.

\section{Socioeconomic resources}

A single question item asked respondent's approximate total household income for the past 12 months. The original 15 household income categories were collapsed into eight categories, recoded to the median value of each category, and rescaled in thousands of dollars [62]. Recoding and rescaling household income provides an intuitive interpretation for the effect of median household income in thousands of dollars rather than in units of the categories [63]. To determine income from savings and investments, two questions asked if the respondent or anyone in the respondent's household received: 1) interest from savings or other bank accounts (other than dividends) and 2) dividend income from stocks or mutual funds or income from rental property, royalty, estates, or trusts. Response options for both questions are: 1) Yes, me; 2) Yes, someone else; 3) Yes, someone else and me; and 4) No. Affirmative responses to the two questions are recoded into dummy variables and summed. A derived measure of educational attainment includes 11 response options that served as a measure of educational attainment. Occupational status was recoded 
into corresponding 2000 Census Occupational Codes by NCES staff. In the analyses the Census Occupational Codes were recoded into Nam-Powers-Boyd Occupational Status Scale values that range from 1 (lowest status) to 100 (highest status) [64-67].

\section{Relational social class}

Employment status is a derived variable and the original six response categories include: 1) Employed Full Time, 2) Employed Part Time, 3) Employed Not at Work, 4) Unemployed Looking for Work, 5) Unemployed Not Looking for Work, and 6) Out of Labor Force. The first three response options were collapsed into an "Employed" category. The last three response options were collapsed into an "Unemployed" category. In our analyses, "Unemployed" was the excluded category. A derived measure of voting in the 2000 election included the response options: 1) Not a Citizen 2) Did Not Vote, 3) Voted, and 4) Do Not Remember. Response categories are recoded into dummy variables and respondents who voted were the excluded category in the analyses.

Respondents indicated the amount of information about current events, public affairs and the government from six sources including: 1) Newspapers, 2) Magazines, 3) Internet, 4) Radio and Television, 5) Books or Brochures, and 6) Family Members, Friends, or Co-workers. The response options for each source of information were: $1=$ A Lot, $2=$ Some, $3=$ A Little, and $4=$ None. Response options were reverse coded and higher values indicate a greater amount of information and then averaged across the six sources for non-missing values only. Respondents were asked how often they used a library for any reason. Response options included: 1) Daily, 2) Weekly, 3) Monthly, 4) Once or Twice a Year, and 5) Never. To create equivalent library use categories, the first three responses were collapsed and recoded into a dummy variable for "Frequent" library use. The response options Once or Twice a Year and Never were each recoded into dummy variables. In the analyses, "Never" was the excluded category.

Two question items provide the measure of volunteer activity. First, respondents were asked if they gave any unpaid time as a volunteer to a group or organization during the past year. The response options were recoded into a dummy variable (i.e., $0=$ No, $1=$ Yes). Second, if the respondent volunteered a follow up question asked how often they volunteered and included the response options: 1) Most days, 2) A few days a week, 3) About once a week, and 4) Less than once a week. The combined response options were reverse coded so higher values indicate a higher level of volunteer activity. To create equivalent volunteer activity categories, the response options Most days, A few days a week, and About once a week were collapsed and recoded into a dummy variable for "Frequent" volunteer activity. The response options Less than once a week and Never were each recoded into dummy variables. In the analyses, the "Never" volunteer was the excluded category.

\section{Social resources}

Language spoken is a derived measure from responses to two questions: "When you were growing up, what language or languages were usually spoken in your home?" and "Which language do you often speak now?" Respondents who indicated English for both questions were recoded as only English speaking. Respondents who spoke Spanish growing up and now speak English were recoded as Spanish/English as Second Language (ESL). Respondents who spoke Spanish growing up and only spoke Spanish were recoded as Speaking Spanish Only. The remaining respondents who spoke any other language growing up and now speak English were recoded as Other Language Spoken ESL. Native English speaking respondents are the excluded category in the analyses.

Marital status is a derived measure and respondents were categorized as either: 1) Never Married, 2) Married or Living as Married, and 3) Separated/Divorced/Widowed. The three categories were recoded into dummy variables and married or living as married was the excluded category. Respondents indicated the amount of information about health issues obtained from six sources. The sources included: 1) Newspapers, 2) Magazines, 3) Internet, 4) Radio and Television, 5) Books or Brochures, and 6) Family Members, Friends, or Co-workers. The response options for each source of information were: 1 = A lot, 2 = Some, 3 $=\mathrm{A}$ little, or $4=$ None. Cronbach's alpha analysis revealed Newspapers, Magazines, and Books or Brochures are a reliable measure for source of health information $(\alpha=0.71)$. Response options were reverse coded and higher values indicate a greater amount of information and then averaged for the three sources for non-missing values only.

\section{Data analysis}

Two analytical techniques were employed in the research. First, weighted descriptive statistics were estimated for all variables. Bivariate correlation matrices (available upon request) do not reveal multicollinearity among the predictor variables. Second, a series of weighted multivariate Ordinary Least Squares (OLS) regression analyses were used as the dependent variable was a continuous measure. Given the multi-stratified cluster sampling design in the NAAL, all analyses were conducted in STATA 12 [68] to include sampling weights.

\section{Results}

\section{Descriptive statistics}

Table 1 displays the weighted descriptive statistics for all variables. On average, respondents were 45 years of age, 
Table 1 Descriptive statistics for demographic, socioeconomic resources, and health literacy score (Weighted) ${ }^{a}$

\begin{tabular}{|c|c|c|c|c|c|c|}
\hline \multirow{2}{*}{$\begin{array}{c}\text { Demographic } \\
\text { Age }\end{array}$} & \multirow{2}{*}{$\frac{\text { Mean }}{44.9}$} & \multirow{2}{*}{$\frac{\text { Lin. Std. Err. }}{0.29}$} & \multicolumn{2}{|c|}{ [95 \% Conf. Interval] } & \multirow{2}{*}{$\begin{array}{l}\text { Min } \\
18.00\end{array}$} & \multirow{2}{*}{$\frac{\text { Max }}{100.00}$} \\
\hline & & & 44.33 & 45.48 & & \\
\hline Men & 0.48 & 0.01 & 0.46 & 0.49 & 0.00 & 1.00 \\
\hline Women & 0.52 & 0.01 & 0.51 & 0.54 & 0.00 & 1.00 \\
\hline White & 0.71 & 0.02 & 0.67 & 0.74 & 0.00 & 1.00 \\
\hline African-American & 0.12 & 0.01 & 0.09 & 0.14 & 0.00 & 1.00 \\
\hline Foreign Born Hispanic/Latino & 0.08 & 0.01 & 0.06 & 0.10 & 0.00 & 1.00 \\
\hline Native Born Hispanic/Latino & 0.05 & 0.01 & 0.03 & 0.06 & 0.00 & 1.00 \\
\hline Asian/Pacific Islander & 0.03 & 0.01 & 0.02 & 0.04 & 0.00 & 1.00 \\
\hline American Indian/Alaskan Native & 0.01 & 0.00 & 0.00 & 0.01 & 0.00 & 1.00 \\
\hline Multiracial & 0.01 & 0.00 & 0.01 & 0.02 & 0.00 & 1.00 \\
\hline \multicolumn{7}{|l|}{ Socioeconomic Resources } \\
\hline Median Household Income (in \$1000) & 48819.66 & 1001.99 & 46840.24 & 50799.09 & 0.00 & 124999.50 \\
\hline Num. Inc. Sources From Savings/Investments & 0.69 & 0.02 & 0.65 & 0.74 & 0.00 & 2.00 \\
\hline Educational Attainment & 5.59 & 0.08 & 5.44 & 5.74 & 1.00 & 11.00 \\
\hline Nam Powers Boyd Occupational Score & 53.36 & 0.56 & 52.25 & 54.46 & 0.00 & 100.00 \\
\hline \multicolumn{7}{|l|}{ Relational Social Class } \\
\hline \multicolumn{7}{|l|}{ Employment Status } \\
\hline Employed & 0.66 & 0.01 & 0.64 & 0.67 & 0.00 & 1.00 \\
\hline Unemployed/Out of Labor Force & 0.34 & 0.01 & 0.33 & 0.36 & 0.00 & 1.00 \\
\hline \multicolumn{7}{|l|}{ Voted in 2000} \\
\hline Not a Citizen & 0.08 & 0.01 & 0.06 & 0.10 & 0.00 & 1.00 \\
\hline Did Not Vote & 0.30 & 0.01 & 0.29 & 0.32 & 0.00 & 1.00 \\
\hline Voted & 0.58 & 0.01 & 0.56 & 0.60 & 0.00 & 1.00 \\
\hline Do Not Remember & 0.04 & 0.00 & 0.03 & 0.04 & 0.00 & 1.00 \\
\hline Current Affairs/Political/Govt. Info. & 2.64 & 0.01 & 2.62 & 2.66 & 1.00 & 4.00 \\
\hline \multicolumn{7}{|l|}{ Source } \\
\hline \multicolumn{7}{|l|}{ Library Use } \\
\hline Frequent & 0.33 & 0.01 & 0.32 & 0.35 & 0.00 & 1.00 \\
\hline Occasional & 0.33 & 0.01 & 0.31 & 0.34 & 0.00 & 1.00 \\
\hline Never Use Library & 0.34 & 0.01 & 0.32 & 0.36 & 0.00 & 1.00 \\
\hline \multicolumn{7}{|l|}{ Volunteer Activity } \\
\hline Frequent & 0.17 & 0.01 & 0.16 & 0.18 & 0.00 & 1.00 \\
\hline Occasional & 0.21 & 0.01 & 0.19 & 0.22 & 0.00 & 1.00 \\
\hline Never & 0.62 & 0.01 & 0.60 & 0.64 & 0.00 & 1.00 \\
\hline \multicolumn{7}{|l|}{ Social Resources } \\
\hline \multicolumn{7}{|l|}{ Language Spoken } \\
\hline Native English Speaker & 0.84 & 0.01 & 0.81 & 0.87 & 0.00 & 1.00 \\
\hline Spanish/ESL & 0.04 & 0.00 & 0.03 & 0.04 & 0.00 & 1.00 \\
\hline Speaks Only Spanish & 0.05 & 0.00 & 0.04 & 0.06 & 0.00 & 1.00 \\
\hline Other Language Spoken ESL & 0.08 & 0.01 & 0.06 & 0.10 & 0.00 & 1.00 \\
\hline \multicolumn{7}{|l|}{ Marital Status } \\
\hline Never Married & 0.21 & 0.01 & 0.19 & 0.22 & 0.00 & 1.00 \\
\hline Married/Living as Married & 0.60 & 0.01 & 0.59 & 0.62 & 0.00 & 1.00 \\
\hline
\end{tabular}


Table 1 Descriptive statistics for demographic, socioeconomic resources, and health literacy score (Weighted) (Continued)

\begin{tabular}{|c|c|c|c|c|c|c|}
\hline Separated/Divorced/widowed & 0.19 & 0.01 & 0.18 & 0.20 & 0.00 & 1.00 \\
\hline Health Information Source & 2.49 & 0.01 & 2.46 & 2.51 & 1.00 & 4.00 \\
\hline Health Literacy Score & 243.10 & 0.86 & 241.39 & 244.81 & 89.74 & 336.38 \\
\hline
\end{tabular}

${ }^{a}$ Source: The National Assessment of Adult Literacy (NAAL) 2003. Respondents 18 years of age and older. N 14,592

female, and white. The average median household income was approximately $\$ 49,000$ and more than half of respondents received additional income from savings and/or investments. The majority of respondents were high school graduates, employed, and voted in the 2000 election. On average, respondents obtained a lot of their information about current affairs from multiple sources and approximately a third of respondents frequently used a library but the majority did not volunteer. On the whole, respondents were native English speakers, married or living as a married couple, and obtained a lot of their health information from multiple sources.

\section{Multivariate analyses}

A series of weighted Ordinary Least Squares (OLS) regression models predicting health literacy level are displayed in Table 2. Examining the coefficient for measures in Model 1, age was significant and negatively associated with health literacy level. Moreover, age maintains a negative, significant, and robust association with health literacy across Models 1-5. Women's health literacy scores were nearly five points higher than the scores of men (Model 1). The pattern remained consistent across Models 1-5. African Americans, Foreign Born Hispanic/Latinos, and Native Born Hispanic/Latinos have health literacy scores that were significantly lower compared to Whites (Model 1). Next, the coefficients for Asian/Pacific Islanders, Native Americans, and Multiracial respondents were also lower than the scores for Whites, but this pattern was explained by variables in the full model (Model 5), in particular the social resource measures. In the full model, the baseline coefficient for Asian/ Pacific Islanders was reduced by 58 and $54 \%$ for Native Americans. The overall model accounts for $13.6 \%$ of the variation in the health literacy scores.

Health literacy level increased by a quarter of a point for every additional thousand dollars (\$1000) in median household income and increased six points with each additional source of income from savings and investments (Model 2). The addition of income and wealth measures accounted for $21.3 \%$ of the variation in health literacy scores which represents a $56.6 \%$ increase over the baseline model. Respondents' health literacy scores increased by nearly four points for each additional level of educational attainment, net of other variables in the model (Model 3). As an individual's occupational prestige increased there was approximately a one-point increase in health literacy scores. The addition of educational attainment and occupational prestige reduced the effect of income from savings and investments by $44.91 \%$; but the effect remains statistically significant. Overall, Model 3 accounted for $27.0 \%$ of the variation in health literacy scores.

The measures of civic engagement voting behavior, library use, and volunteering are significant predictors of health literacy (Model 4). Lower health literacy scores were observed for people who were either not citizens or did not vote. The significant negative association remained consistent for those who did not vote (Model 5). Frequent and occasional library use was associated with a four and five point increase, respectively, in health literacy scores (Models 4 and 5). Health literacy scores increased by three points for respondents who frequently volunteered (Model 4) and the significant positive association remained consistent in Model 5.

Health literacy scores were significantly lower for those who grew up speaking Spanish and now speak English, those who speak Spanish only, and those who grew up speaking a language other than English or Spanish (Model 5). Health literacy was significantly lower for respondents who never married compared to married or co-habitating respondents. Model 5 accounted for $28.6 \%$ of the variation in health literacy scores which represented a $110.3 \%$ increase over the baseline model. Overall, the results suggest that measures of relational social class and social resources improve our understanding of disparities in health literacy.

\section{Discussion}

In this study, we identify social determinants of low health literacy as well as individual assets that promote health literacy. In particular, our findings add new insights on the connection between relational social class and health literacy. Voting, volunteering, and library use are associated with higher health literacy levels, net of demographic and objective SES resources measures. Zarcadoolas and colleagues [69] multidimensional model of health literacy emphasizes the importance of political or civic literacy. Civic literacy enables citizens to become aware of health issues and involved in the decisionmaking processes through civic and social channels. Our results suggest that voters may act to support or oppose governmental influence on health policy. The positive effect of civic engagement on health literacy suggests that 
Table 2 Ordinary least squares regression of health literacy score on demographic, socioeconomic resources, \& social resources (Weighted) $)^{\mathrm{a}}$

\begin{tabular}{|c|c|c|c|c|c|}
\hline & Model 1 & Model 2 & Model 3 & Model 4 & Model 5 \\
\hline \multicolumn{6}{|l|}{ Demographic } \\
\hline \multirow[t]{2}{*}{ Age } & $-0.567^{* * *}$ & $-0.569^{* * *}$ & $-0.472^{* * *}$ & $-0.493^{* * *}$ & $-0.518^{* * *}$ \\
\hline & $(-0.230)$ & $(-0.230)$ & $(-0.191)$ & $(-0.200)$ & $(-0.210)$ \\
\hline \multirow[t]{2}{*}{ Female } & $4.713^{* * *}$ & $6.583^{* * *}$ & $5.968^{* * *}$ & $5.281^{* * *}$ & $4.924^{* * *}$ \\
\hline & $(0.056)$ & $(0.079)$ & $(0.071)$ & $(0.063)$ & $(0.059)$ \\
\hline \multirow[t]{2}{*}{ African American } & $-25.90^{* * *}$ & $-17.02^{* * *}$ & $-16.31^{* * *}$ & $-16.52^{* * *}$ & $-16.48^{* * *}$ \\
\hline & $(-0.195)$ & $(-0.128)$ & $(-0.123)$ & $(-0.124)$ & $(-0.124)$ \\
\hline \multirow[t]{2}{*}{ Foreign Born Hispanic/Latino } & $-44.49^{* * *}$ & $-33.59^{* * *}$ & $-27.96^{* * *}$ & $-22.22^{* * *}$ & $-11.45^{* * *}$ \\
\hline & $(-0.279)$ & $(-0.211)$ & $(-0.176)$ & $(-0.139)$ & $(-0.072)$ \\
\hline \multirow[t]{2}{*}{ Native Born Hispanic/Latino } & $-18.36^{* * *}$ & $-10.85^{* * *}$ & $-9.265^{* * *}$ & $-9.534^{* * *}$ & $-5.620^{*}$ \\
\hline & $(-0.092)$ & $(-0.054)$ & $(-0.046)$ & $(-0.048)$ & $(-0.028)$ \\
\hline \multirow[t]{2}{*}{ Asian/Pacific Islander } & $-8.776^{*}$ & $-8.474^{*}$ & $-12.78^{* * *}$ & $-9.313^{* *}$ & -3.665 \\
\hline & $(-0.037)$ & $(-0.036)$ & $(-0.054)$ & $(-0.039)$ & $(-0.015)$ \\
\hline \multirow[t]{2}{*}{ American Indian/Alaskan Native } & $-22.58^{* *}$ & -12.00 & -11.36 & -11.76 & -10.43 \\
\hline & $(-0.045)$ & $(-0.024)$ & $(-0.023)$ & $(-0.024)$ & $(-0.021)$ \\
\hline \multirow[t]{2}{*}{ Multiracial } & $-13.04^{* *}$ & $-8.315^{*}$ & $-7.476^{*}$ & $-7.571^{*}$ & $-7.265+$ \\
\hline & $(-0.037)$ & $(-0.024)$ & $(-0.021)$ & $(-0.022)$ & $(-0.021)$ \\
\hline \multicolumn{6}{|l|}{ Socioeconomic Resources } \\
\hline \multirow[t]{2}{*}{ Median Household Income (in \$1000) } & & $0.248^{* * *}$ & $0.131^{* * *}$ & $0.116^{* * *}$ & $0.108^{* * *}$ \\
\hline & & $(0.219)$ & $(0.116)$ & $(0.103)$ & $(0.095)$ \\
\hline \multirow[t]{2}{*}{ Income From Savings/Investments } & & $6.391 * * *$ & $3.517^{* * *}$ & $3.011 * * *$ & $3.053^{* * *}$ \\
\hline & & $(0.125)$ & $(0.069)$ & $(0.059)$ & $(0.060)$ \\
\hline \multirow[t]{2}{*}{ Educational Attainment } & & & $3.810^{* * *}$ & $3.318^{* * *}$ & $3.281^{* * *}$ \\
\hline & & & $(0.264)$ & $(0.230)$ & $(0.227)$ \\
\hline \multirow[t]{2}{*}{ Nam Powers Boyd Occupational Score } & & & $0.0663^{* * *}$ & $0.0481^{*}$ & $0.0465^{*}$ \\
\hline & & & $(0.055)$ & $(0.040)$ & $(0.039)$ \\
\hline \multicolumn{6}{|l|}{ Relational Social Class } \\
\hline \multirow[t]{2}{*}{ Employed } & & & & 1.757 & 1.437 \\
\hline & & & & $(0.020)$ & $(0.016)$ \\
\hline \multicolumn{6}{|l|}{ Voted in 2000} \\
\hline \multirow[t]{2}{*}{ Not a Citizen } & & & & $-9.106^{* * *}$ & -2.797 \\
\hline & & & & $(-0.059)$ & $(-0.018)$ \\
\hline \multirow[t]{2}{*}{ Did Not Vote } & & & & $-3.925^{* *}$ & $-3.567^{* *}$ \\
\hline & & & & $(-0.043)$ & $(-0.039)$ \\
\hline \multirow[t]{2}{*}{ Do Not Remember } & & & & -1.728 & -1.231 \\
\hline & & & & $(-0.008)$ & $(-0.005)$ \\
\hline \multirow[t]{2}{*}{ Current Aff/Pol/Govt. Info } & & & & $1.523+$ & 0.704 \\
\hline & & & & $(0.019)$ & $(0.009)$ \\
\hline \multicolumn{6}{|l|}{ Library Use } \\
\hline \multirow[t]{2}{*}{ Frequent Library Use } & & & & $4.118^{* *}$ & $4.098^{* *}$ \\
\hline & & & & $(0.046)$ & $(0.046)$ \\
\hline \multirow[t]{2}{*}{ Occasional Library Use } & & & & $5.983^{* * *}$ & $5.642^{* * *}$ \\
\hline & & & & $(0.067)$ & $(0.063)$ \\
\hline
\end{tabular}


Table 2 Ordinary least squares regression of health literacy score on demographic, socioeconomic resources, \& social resources (Weighted) $^{\mathrm{a}}$ (Continued)

\begin{tabular}{|c|c|c|c|c|c|}
\hline \multicolumn{6}{|l|}{ Volunteer Activity } \\
\hline \multirow[t]{2}{*}{ Frequently Volunteer } & & & & $3.412^{*}$ & $3.200+$ \\
\hline & & & & $(0.031)$ & $(0.029)$ \\
\hline \multirow[t]{2}{*}{ Occasionally Volunteer } & & & & 2.238 & 1.820 \\
\hline & & & & $(0.022)$ & $(0.018)$ \\
\hline \multicolumn{6}{|l|}{ Social Resources } \\
\hline \multicolumn{6}{|l|}{ Language Spoken } \\
\hline \multirow[t]{2}{*}{ Spanish/ESL } & & & & & $-5.824+$ \\
\hline & & & & & $(-0.025)$ \\
\hline \multirow[t]{2}{*}{ Speaks Only Spanish } & & & & & $-9.885^{*}$ \\
\hline & & & & & $(-0.051)$ \\
\hline \multirow[t]{2}{*}{ Other Language Spoken ESL } & & & & & $-19.11^{* * *}$ \\
\hline & & & & & $(-0.121)$ \\
\hline \multicolumn{6}{|l|}{ Marital Status } \\
\hline \multirow[t]{2}{*}{ Never Married } & & & & & $-3.574^{* *}$ \\
\hline & & & & & $(-0.034)$ \\
\hline \multirow[t]{2}{*}{ Separated/Divorced/Widowed } & & & & & -0.780 \\
\hline & & & & & $(-0.007)$ \\
\hline \multirow[t]{2}{*}{ Health Information Source } & & & & & 0.929 \\
\hline & & & & & $(0.017)$ \\
\hline Constant & $274.6^{* * *}$ & $253.9 * * *$ & $232.2^{* * *}$ & $230.3^{* * *}$ & $233.8^{* * *}$ \\
\hline R-squared & 0.136 & 0.213 & 0.270 & 0.279 & 0.286 \\
\hline $\mathrm{F}$ & $101.4^{* * *}$ & $231.9 * * *$ & $252.2^{* * *}$ & $160.3^{* * *}$ & $126.1^{* * *}$ \\
\hline
\end{tabular}

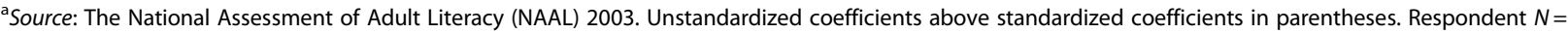
$14,592 .+p<0.05 * p<0.01 * * p<0.001 * * * 00.0001$

participation in important civic activities like voting and volunteering involve connecting with one's community in ways that promote health literacy or attention to health affairs. Civic engagement creates social ties by connecting individuals to a larger community or movement. In turn, social connections provide an opportunity to become aware of as well as increase confidence and willingness to seek out available health resources. Understanding how positive health literacy flows from civic engagement may offer a counterpoint to a risk approach to health literacy which focuses on a deficit model.

The findings also reveal that social resources are associated with higher health literacy. The findings related to language are mostly what we would expect; yet, there are some finer points worth noting. The majority of health and healthcare information in the United States is written and spoken in English and translations of the information are also widely available in Spanish. Therefore, as a social resource, it is not surprising that respondents who learn English in childhood have a relative advantage over those who are learning or do not understand English. What is surprising is that Spanish speakers who have not learned English have significantly higher skills than those from other language groups who have learned English. The finding suggests two points of interest. First, providing information in Spanish is important for the Spanish speaking community. Second, the language instruction currently in place for speakers of other languages may not do enough to bring them up to the health literacy levels of others. The results support continued and improved efforts in creating multilingual health information and providing free and high quality ESOL (English for Speakers of Other Languages) in adult education programs [70].

Marriage is a social resource that benefits health literacy by encouraging healthy behaviors. The gender and health literature provides insight into the relationship between marital status and health literacy. Marriage, or living as a married couple, fosters social interaction and an expansion of social networks as well as economic support to pay for healthcare services $[52,53]$. It is also possible that, because women maintain more consistent social relationships throughout life, social connections provide women with the same types of benefits that we 
see for people who are married or living as married. Social interaction tends to improve one's health literacy skills and subsequently prolong one's lifespan.

Consistent with previous research, we found that as people age their health literacy declines, that health literacy is higher for women compared to men, and that racial and ethnic minorities have lower health literacy compared to whites. The underlying assumption is that the lower health literacy for ethnic minorities is due to lower socioeconomic status, lower educational attainment, employment status, and language barriers. However, our results show that, minorities have consistently lower health literacy scores when compared to whites who with the same educational attainment, income, gender and age. The disadvantage of being a minority cuts across many of the protective features that might account for their lower health literacy. Other studies have not revealed this persistence in health literacy disparities attributable solely to racial/ethnic disparities. Our findings reveal that nativity has a protective influence, even for the most disadvantaged racial groups. While both native born and foreign born Hispanics had lower health literacy levels, foreign born Hispanics had significantly lower scores than even their native born counterparts. The differences may be a result of native born Hispanics' assimilation of language and culture in the United States.

Household income and additional income from savings and/or investments are each independently associated with a significant increase in health literacy scores. What is notable, however, is that the association with higher scores is greater for these additional sources of wealth than it is for an overall increase in median household income. Health literacy scores increased by a quarter of a percent for every additional $\$ 1000$ in median household income; yet, each additional source of wealth from savings and/or investments is associated with a six full point increase in health literacy scores. The significant and positive effect of increasing levels of educational attainment concurs with previous research that education has an independent and positive relationship with individual levels of health literacy [10, 12, 20,30].

The limitations of the existing research should be considered when interpreting findings. First, the NAAL health literacy question items only focus on the functional aspect of health literacy and do not provide an assessment of oral communication ability and/or critical analytic ability. In addition, the assessment does not reflect the ability to communicate or the ability to determine the quality of health information and how an individual might make decisions or change behavior based on health information. Second, the NAAL is a secondary cross-sectional data set collected over a decade ago. Thus, the present analyses cannot address causal relationships; instead, a longitudinal research design is appropriate to examine how change in social, economic, and structural factors impact change in health literacy level over time [71, 72]. Moreover, we caution that our results may not reflect the relationship between health literacy disparities and health inequities in the United States given the systemic changes in the system of health care as a result of provisions in the 2010 Patient Protection and Affordable Care Act [73, 74]. Despite these limitations, the present research adds significant value to clarify the distribution of disparities in health literacy and identify opportunities to reduce inequity.

\section{Conclusions}

Health literacy may be viewed as several integrated concepts relating to what people need to be able to participate in effective decision-making about health for themselves, and their families [75]. Earlier definitions, such as the National Academy of Medicine's [2], focus on individual deficits (and subsequent risk) within clinical settings [76]. Definitions from other countries conceptualize health literacy as an asset for good health, not just in clinical settings, but in everyday life [31, 77]. Our findings support a broader understanding of health literacy in the United States.

The results presented herein provide strong evidence that disparities in health literacy cut across demographic and socioeconomic groups, level of civic engagement through voting and volunteering, and available social resources. To increase equity in health literacy and health outcomes will necessitate a fundamental shift in perspective among health literacy practitioners and researchers in the United Sates. There remains a critical need to develop a theoretically driven conceptual definition of health literacy as a social construct [78-80]. Instead of focusing on health literacy as an individual deficit; a shifting perspective of health literacy emphasizes the importance of social context, the role of social interaction, and the creation of social connections as an asset. These new insights in disparities in health literacy can provide a focus for creating relevant interventions. For example, interventions to increase health literacy may include components to improve self-efficacy, personal empowerment, civic engagement and social interactions. Health literacy interventions must focus on how health literacy skills are used on a daily basis. There is a need for continuing efforts to improve dissemination of health information in plain language, Spanish and other languages, and improve the quality and accessibility of English language and literacy instruction.

\section{Endnotes}

${ }^{1}$ VisualDF is a free, open-source program available at http://www4.ncsu.edu/ awmeade/VisualDF/Main.htm to compute effect size indices of differential functioning of items and test scales. 


\section{Abbreviations}

2PL: Two parameter logistic; CT: Classical test theory; GRM: Graded response model; IRT: Item response theory; NAAL: National assessment of adult literacy; NCES: National center for education statistics; OLS: Ordinary least squares

\section{Acknowledgments}

A previous version of the research was presented at the 5th Annual Health Literacy Research Conference in Washington, D.C. The authors wish to thank Jolie Haun, Shelia R. Cotten, Bonnie Braun, and Monica E. Williams for their valuable feedback. Any and all mistakes are solely the responsibility of the authors.

\section{Funding}

Not applicable.

\section{Availability of data and materials}

The data that support the findings of this study are available from the National Center for Education Statistics (NCES) but restrictions apply to the availability of these data, which were used under license for the current study, and so are not publicly available. A public access version of the data are, however, available from the National Center for Education Statistics (NCES) https://nces.ed.gov/naal/datafiles.asp.

\section{Authors' contributions}

The authors RVR, MST, JM, and AB worked on the conception, study design, and the final article composition. RVR and MST worked on the methods, data analysis, and results. JM and AB worked on the discussion and provided continuous critical review of the overall manuscript. RVR is the first author. All the authors read and approved the final manuscript.

\section{Competing interests}

The authors declare that they have no competing interests.

\section{Consent for publication}

Not applicable.

\section{Ethics and consent to participate}

The data analyses were performed with approval from the Institutional Review Board at North Carolina State University. Written informed consent was obtained by the National Center for Education Statistics (NCES) as part of the National Assessment of Adult Literacy (NAAL). The written informed consent for participation in the NAAL, sampling design, and complete sample size are described in Jin Y, Greenberg E, Baer J. 2003 National Assessment of Adult Literacy: Restricted-Use Data File User's Guide (NCES 2007-492). Washington, DC: National Center for Education Statistics 2007.

\section{Author details}

${ }^{1}$ Department of Media \& Information, Michigan State University, 409 Comm Arts, 404 Wilson Road, East Lansing, Ml 48824, USA. ²Department of Sociology \& Anthropology, North Carolina State University, Raleigh, NC, USA. ${ }^{3}$ McKinney Health Literacy Services, Cambridge, MA, USA. ${ }^{4}$ Deakin Population Health SRC, Faculty of Health, Deakin University, Melbourne, VIC, Australia.

Received: 10 March 2016 Accepted: 2 September 2016

Published online: 13 September 2016

\section{References}

1. Nutbeam D. The evolving concept of health literacy. Soc Sci Med. 2008;67(12):2072-8

2. Nielsen-Bohlman L, Panzer AM, Kindig DA. Health Literacy: A Prescription to End Confusion. Washington, D.C: The National Academies Press; 2004

3. Krieger N, Williams DR, Moss NE. Measuring Social Class in US Public Health Research: Concepts, Methodologies, and Guidelines. Annu Rev Public Health. 1997:18(1):341-78.

4. Muntaner C, Borrell C, Vanroelen C, Chung H, Benach J, Kim $\mathrm{H}_{\text {, Ng E. }}$ Employment relations, social class and health: A review and analysis of conceptual and measurement alternatives. Soc Sci Med. 2010;71(12):2130-40.

5. Phelan JC, Link BG, Tehranifar P. Social Conditions as Fundamental Causes of Health Inequalities. J Health Soc Behav. 2010;51(1 suppl):S28-S40-S28-S40.
6. Kutner M, Greenberg E, Baer J. A First Look at the Literacy of America's Adults in the 21st Century (NCES 2006-470). Washington, DC: National Center for Educational Statistics United States Department of Education; 2006.

7. Pleasant A. A Second Look at the Health Literacy of American Adults and the National Assessment of Adult Literacy. Can J Public Health. 2008;98(4): 337-40.

8. Sørensen K, Pelikan JM, Röthlin F, Ganahl K, Slonska Z, Doyle G, Fullam J, Kondilis B, Agrafiotis D, Uiters E, et al. Health literacy in Europe: comparative results of the European health literacy survey (HLS-EU). Eur J Public Health. 2015;25(6):1053-8.

9. van der Heide I, Rademakers J, Schipper M, Droomers M, Sorensen K, Uiters E. Health literacy of Dutch adults: a cross sectional survey. BMC Public Health. 2013;13(1):179.

10. Ayotte BJ, Allaire JC, Bosworth $\mathrm{H}$. The Associations of Patient Demographic Characteristics and Health Information Recall: The Mediating Role of Health Literacy. Aging Neuropsychol Cogn. 2009;16(4):419-32.

11. Baker DW, Gazmararian JA, Williams MV, Scott T, Parker RM, Green D, Ren J, Peel J. Functional Health Literacy and the Risk of Hospital Admission Among Medicare Managed Care Enrollees. Am J Public Health. 2002;92(8):1278-83.

12. Gazmararian JA, Baker DW, Williams MV, Parker RM, Scott TL, Green DC, Fehrenbach SN, Ren J, Koplan JP. Health Literacy Among Medicare Enrollees in a Managed Care Organization. JAMA. 1999;281(6):545-51.

13. Sudore RL, Yaffe K, Satter Field S, Harris TB, Mehta KM, Simonsick EM, Newman AB, Rosano C, Rooks R, Rubin SM, et al. Limited Literacy and Mortality in the Elderly The Health, Aging, and Body Composition Study. J Gen Intern Med. 2006;21(8):806-12.

14. Howard DH, Sentell T, Gazmararian JA. Impact of Health Literacy on Socioeconomic and Racial Differences in Health in an Elderly Population. J Gen Intern Med. 2006;21(8):857-61.

15. Sentell TL, Halpin HA. Importance of Adult Literacy in Understanding Health Disparities. J Gen Intern Med. 2006;21(8):862-6.

16. Dupre ME, Goerge LK. Exceptions to the Rule: Exceptional Health Among the Disadvantaged. Res Aging. 2011;33(2):115-44.

17. Fiscella K, Williams DR. Health Disparities Based on Socioeconomic Inequities: Implications for Urban Health Care. Acad Med. 2004;79(12):1139-47.

18. House JS, Leplowski JM, Kineey AM, Mero RP, Kessler RC, Herzog AR. The Social Stratification of Aging and Health. J Health Soc Behav. 1994;35(3): 213-34

19. Jeppesen KM, Coyle JD, Miser WF. Screening Questions to Predict Limited Health Literacy: A Cross-Sectional Study of Patients With Diabetes Mellitus. Ann Fam Med. 2009:7(1):24-31.

20. Schillinger D, Grumbach K, Piette J, Wang F, Osmond D, Daher C, Palacios J, Sullivan GD, Bindman AB. Association of Health Literacy With Diabetes Outcomes. JAMA. 2002;288(4):475-82.

21. Williams DR, Collins C. US Socioeconomic And Racial Differences in Health: Patterns and Explanations. Annu Rev Sociol. 1995;21:349-86.

22. Cummings $J \mathrm{~L}$, Braboy Jackson P. Race, gender, and SES disparities in selfassessed health, 1974-2004. Res Aging. 2008;30(2):137.

23. Ferraro KF, Farmer MM. Utility of Health Data from Social Survey: Is There a Gold Standard for Measuring Morbidity? Am Sociol Rev. 1999;64(2):303-15.

24. McGee DL, Liao Y, Cao G, Cooper RS. Self-reported Health Status and Mortality in a Multiethnic US Cohort. Am J Epidemiol. 1999;149(1):41-6.

25. Shi L, Starfield B, Politzer R, Regan J. Primary Care, Self-rated Health, and Reductions in Social Disparities in Health. Health Serv Res. 2002;37(3):529-50.

26. Verbrugge LM. Gender and Health: An Update on Hypotheses and Evidence. J Health Soc Behav. 1985;26(3):156-82.

27. Williams DR. The Health of Men: Structured Inequalities and Opportunities. Am J Public Health. 2003;93(5):724-31.

28. von Wagner C, Knight K, Steptoe A, Wardle J. Functional Health Literacy and Health-Promoting Behaviour in a National Sample of British Adults. I Epidemiol Community Health. 2007;61:1086-90.

29. Mirowsky J, Ross CE. Education, social status, and health. Aldine de Gruyter; 2003.

30. Benson JG, Forman WB. Comprehension of Written Health Care Information in an Affluent Geriatric Retirement Community: Use of the Test of Functional Health Literacy. Gerontology. 2002;48(2):93-7.

31. Kickbusch I. Health literacy: addressing the health and education divide. Health Promot Int. 2001;16(3):289-97.

32. Braveman PA, Cubbin C, Egerter $S$, et al. Socioeconomic status in health research: One size does not fit all. JAMA. 2005;294(22):2879-88. 
33. Adler NE, Ostrove JM. Socioeconomic Status and Health: What We Know and What We Don't. Ann N Y Acad Sci. 1999;896(1):3-15.

34. Evans W, Wolfe B, Adler N. The SES and Health Gradient: A Brief Review of the Literature. In: Wolfe B, Evans W, Seeman TE, editors. The Biological Consequences of Socioeconomic Inequalities. New York, NY: Russell Sage Foundation; 2012.

35. Oakes JM, Rossi PH. The measurement of SES in health research: current practice and steps toward a new approach. Soc Sci Med. 2003;56(4):769-84.

36. Krieger N. Discrimination and health. Soc Epidemiol. 2000;1:36-75.

37. Wagle U. Multidimensional Poverty Measurement with Economic Well-being, Capability, and Social Inclusion: A Case from Kathmandu, Nepal. J Hum Dev. 2005;6(3):301-28.

38. Wagle U. Multidimensional poverty measurement: Concepts and applications, vol. 4: New York, NY: Springer Verlag; 2008.

39. Kleiner S, Pavalko EK. Clocking In: The Organization of Work Time and Health in the United States. Social Forces. 2010;88(3):1463-86.

40. Ross CE, Mirowsky J. Does Employment Affect Health? J Health Soc Behav. 1995;36(3):230-43.

41. Verba S, Schlozman KL, Brady H, Nie NH. Citizen activity: who participates? What do they say? Am Pol Sci Rev. 1993;303-318.

42. Mattila M, Söderlund P, Wass H, Rapeli L. Healthy voting: The effect of self-reported health on turnout in 30 countries. Elect Stud. 2013;32(4):886-91.

43. Szreter S, Woolcock M. Health by association? Social capital, social theory, and the political economy of public health. Int J Epidemiol. 2004;33(4):650-67.

44. Sundquist K, Yang M. Linking social capital and self-rated health: A multilevel analysis of 11,175 men and women in Sweden. Health Place. 2007;13(2):324-34

45. Blakely TA, Kennedy BP, Kawachi I. Socioeconomic inequality in voting participation and self-rated health. Am J Public Health. 2001;91(1):99-104.

46. Becker S, Crandall MD, Fisher KE, Kinney B, Landry C, Rocha A. Opportunity for All: How the American Public Benefits from Internet Access at U.S. Libraries. Washington, D.C: Institute of Museum and Library Services; 2010.

47. Deloitte. 2013 Deloitte Volunteer IMPACT Survey. 2013.

48. Hackl F, Halla M, Pruckner GJ. Volunteering and Income - The Fallacy of the Good Samaritan? Kyklos. 2007;60(1):77-104.

49. Andrulis DP, Brach C. Integrating literacy, culture, and language to improve health care quality for diverse populations. Am J Health Behav. 2007;31:S122-133-S122-133.

50. Fiscella K, Franks P, Doescher MP, Saver BG. Disparities in Health Care by Race, Ethnicity, and Language Among the Insured: Findings From a National Sample. Med Care. 2002;40(1):52-9.

51. Angel RJ, Angel JL, Montez JK. The Work/Health Insurance Nexus: A Weak Link for Mexican-Origin Men*. Soc Sci Q. 2009;90(5):1112-33.

52. Williams K. Has the future of marriage arrived? A contemporary examination of gender, marriage, and psychological well-being. J Health Soc Behav. 2003;470-487.

53. Williams K, Umberson D. Marital Status, Marital Transitions, and Health: A Gendered Life Course Perspective. J Health Soc Behav. 2004;45(1):81-98.

54. Wei M-H. The associations between health literacy, reasons for seeking health information, and information sources utilized by Taiwanese adults. Health Educ J. 2014:73(4):423-34.

55. Jin Y, Greenberg E, Baer J. 2003 National Assessment of Adult Literacy: Restricted-Use Data File User's Guide (NCES 2007-492). In. Edited by U.S. Department of Education NCfES. Washington, DC: National Center for Education Statistics; 2007.

56. Baker FB. The basics of item response theory. 1985. For full text: http://echo.edres.org:8080/irt/baker/.

57. Baldi S, Kutner M, Greenberg E, Jin Y, Baer J, Moore E, Dunleavy E, Berlin M, Mohadjer L, Binzer G, et al. Technical Report and Data File User's Manual for the 2003 National Assessment of Adult Literacy (NCES 2009-476). 2009.

58. Samejima F. Estimation of latent ability using a response pattern of graded scores. PSYCHOMETRIKA. 1970;35(1):139.

59. Meade AW, Lautenschlager GJ. A Comparison of Item Response Theory and Confirmatory Factor Analytic Methodologies for Establishing Measurement Equivalence/Invariance. Organ Res Methods. 2004;7(4):361-88.

60. Meade AW. A taxonomy of effect size measures for the differential functioning of items and scales. J Appl Psychol. 2010;95(4):728-43.

61. Sudano JJ, Baker DW. Explaining US racial/ethnic disparities in health declines and mortality in late middle age: The roles of socioeconomic status, health behaviors, and health insurance. Soc Sci Med. 2006;62(4):909-22
62. Christ SL, Fleming LE, Lee DJ, Muntaner C, Muennig PA, Caban-Martinez AJ. The effects of a psychosocial dimension of socioeconomic position on survival: occupational prestige and mortality among US working adults. Sociol Health IIIn. 2012;34(7):1103-17.

63. Christ SL. In. Rikard RV, Editor; 2012.

64. Nam C, Boyd M. Occupational Status in 2000: Over a Century of Census-Based Measurement. Popul Res Policy Rev. 2004;23:327-58.

65. Deane G, Shin H-J. Technical Report: Comparability of the 2000 and 1990 Census Occupation Codes. In. Lewis Mumford Center for Comparative Urban and Regional Research. Albany, NY: University at Albany; 2002.

66. Meyer PB, Osborne AM. Proposed category system for 1960-2000 Census occupations. 2005.

67. Nam C. Comparison of three occupational scales, Florida State University Center of Population, Working paper. 2000.

68. StataCorp. Stata Statistical Software: Release 12. College Station, TX: StataCorp LP; 2011.

69. Zarcadoolas C, Pleasant A, Greer DS. Advancing Health Literacy: A Framework for Understanding and Action. San Francisco, CA: Josey-Bass; 2006.

70. Santos MG, Handley MA, Omark K, Schillinger D. ESL Participation as a Mechanism for Advancing Health Literacy in Immigrant Communities. J Health Commun. 2014;19(sup2):89-105.

71. Allison PD. Survival analysis using SAS: a practical guide. Cary, NC: Sas Institute; 2010.

72. Singer JD, Willett JB. Applied longitudinal data analysis: Modeling change and event occurrence. New York, NY: Oxford University Press; 2003.

73. Somers SA, Mahadevan R. Health Literacy Implications of the Affordable Care Act. Hamilton, NJ: Center for Health Care Strategies, Inc.; 2010.

74. Weinstein RS, Graham AR, Erps KA, Lopez AM. Health Literacy: The Affordable Care Act Ups the Ante. Am J Med. 2013;126(12):1029-30.

75. Dodson S, Beauchamp A, Batterham RW, Osborne RH. Information sheet 7 : The Ophelia Approach to optimising health literacy. In Ophelia Toolkit: A step-by-step guide for identifying and responding to health literacy needs within local communities. 2014.

76. Peerson A, Saunders M. Health literacy revisited: what do we mean and why does it matter? Health Promot Int. 2009;24(3):285-96.

77. Sorensen K, Van den Broucke S, Fullam J, Doyle G, Pelikan J, Slonska Z, Brand $\mathrm{H}$. Health literacy and public health: A systematic review and integration of definitions and models. BMC Public Health. 2012;12:80.

78. Pleasant A, McKinney J, Rikard RV. Health literacy measurement: A proposed research agenda. J Health Commun. 2011;16(sup3):11-21.

79. Rikard RV, Head R, Thompson MS. Know Your Status: Health Literacy, Self-Efficacy \& HIV Teasting Attitudes. J Behav Soc Sci. 2016;3:52-62.

80. Rikard RV, McKinney J. Where Do We Go From Here With Health Literacy? In: Kopera-Frye K, Editor. Health Literacy Among Older Adults. New York, NY: Springer International Publishing; 2016. 249-264.

\section{Submit your next manuscript to BioMed Central and we will help you at every step:}

- We accept pre-submission inquiries

- Our selector tool helps you to find the most relevant journal

- We provide round the clock customer support

- Convenient online submission

- Thorough peer review

- Inclusion in PubMed and all major indexing services

- Maximum visibility for your research

Submit your manuscript at www.biomedcentral.com/submit 